\title{
Arbóreas medicinais das matas ciliares do Rio Canoas: potencialidade de uso em projetos de restauração
}

\author{
CHAVES, C.L.; MANFREDI, C.S.* \\ Universidade do Planalto Catarinense, Departamento de Ciências Biológicas, Avenida Castelo Branco, 170, Bairro \\ Universitário, Caixa Postal 525, CEP: 88509-900, Lages-Brasil *manfredicoimbra.silvana@gmail.com
}

\begin{abstract}
RESUMO: Este estudo objetivou identificar as espécies arbóreas medicinais das matas ciliares de três pequenas propriedades rurais do município de Urubici-SC, e estabelecer relações entre as características ecológicas das mesmas com as possibilidades de emprego para restauração de ambientes ciliares degradados. Empregou-se o método dos quadrantes, para levantamento dos indivíduos com CAP $\geq 15 \mathrm{~cm}$. Os indivíduos amostrados foram herborizados, depositados no Herbário LUSC e categorizados quanto ao uso medicinal, parte usada, freqüência, síndrome de dispersão (anemocórica, autocórica e zoocórica), grupo ecológico (pioneira, secundária inicial, secundária tardia) e uso para restauração florestal. Dos 240 indivíduos amostrados, 197 indivíduos pertencentes a 22 espécies de 15 famílias botânicas apresentaram potencialidades medicinais. As famílias Euphorbiaceae, Rosaceae, Myrtaceae, Sapindaceae, Lauraceae e Anacardiaceae foram as mais abundantes. Mais de $85 \%$ das espécies com potencial medicinal amostradas apresentaram síndrome de dispersão zoocórica; cerca de $78 \%$ foram incluídas nos grupos ecológicos das secundárias iniciais e pioneiras e cerca de $88 \%$ são recomendadas para restauração. As espécies arbóreas medicinais são bastante freqüentes nas matas ciliares degradadas do Rio Canoas, podendo ser fonte de recursos genéticos para a restauração e adequação das APPs à legislação ambiental, além de se constituírem em produtos florestais não madeireiros passíveis de exploração.
\end{abstract}

Palavras-chave: biodiversidade, Floresta Ombrófila Mista, conservação, plantas medicinais, restauração

\begin{abstract}
Medicinal trees from riparian forests along Canoas River: potential use in restoration projects. This study aimed to identify the medicinal arboreal species from riparian forests at three small farms in Urubici Municipality, Santa Catarina State, Brazil, and relate their ecological features to the possibilities of their use for restoration of degraded riparian environments. In order to survey individuals with circumference at breast height $(\mathrm{CBH}) \geq 15 \mathrm{~cm}$, the quadrant method was adopted. The sampled specimens were herborized, incorporated into the Herbarium LUSC and categorized according to their medicinal use, employed part, frequency, dispersal syndrome (anemochory, autochory and zoochory), ecological group (pioneer, early secondary, late secondary) and use for forest restoration. Of the 240 sampled specimens, 197 belonging to 22 species of 15 families were potentially medicinal. The most abundant families were Euphorbiaceae, Rosaceae, Myrtaceae, Sapindaceae, Lauraceae and Anacardiaceae. More than $85 \%$ potentially medicinal species had zoochoric dispersal syndrome, around $78 \%$ were categorized as early secondary and pioneer, and around $88 \%$ were recommended for restoration. Medicinal arboreal species are quite common in degraded riparian forests along Canoas River. They can provide genetic resources for restoration and adequacy of permanent preservation areas (PPAs) to the environmental legislation; moreover, they are exploitable non-timber forest products.
\end{abstract}

Key words: biodiversity, Araucaria moist forests, conservation, medicinal plants, restoration

Recebido para publicação em 09/03/2009

Aceito para publicação em 12/03/2010

Rev. Bras. PI. Med., Botucatu, v.12, n.3, p.322-332, 2010. 


\section{INTRODUÇÃO}

A utilização de plantas medicinais vem sendo cada vez mais difundida no País, e é possibilitada pela ampla biodiversidade e pela miscigenação das culturas indígena, negra e européia (Oliveira et al., 2003), cujos dados sobre o uso destas plantas encontram-se registrados em vasta bibliografia (Dorigoni et al., 2001; Cruz \& Kaplan, 2004; Alves et al., 2008; Karimi et al., 2008), que representa importante instrumento na triagem de material botânico para avaliação farmacológica.

A população brasileira tem tradição no uso de plantas para tratamento de necessidades básicas em saúde (Brasil, 2006), mas o Brasil apresenta ainda enorme potencial a ser explorado na área de fitoterápicos devido à grande biodiversidade, a qual abrange grande quantidade de espécies endêmicas (Pedroso et al., 2007).

Mesmo com o crescente consumo de plantas medicinais em centros urbanos, por pacientes de todo nível sócio-econômico e cultural (Suyenaga et al., 2007), o emprego ainda predomina em zonas rurais, onde as pessoas têm informações sobre indicações de uso e facilidade de acesso.

A Floresta Atlântica é um imenso reservatório pouco explorado, sendo que em pequenas propriedades rurais situadas nos limites de abrangência estão contidos fragmentos florestais detentores da biodiversidade remanescente (Mariot \& Reis, 2006). O município de Urubici, localizado no Planalto Serrano, apresenta extensas áreas de APPs (Áreas de Preservação Permanente) em função das características do relevo, e nele se concentram nascentes de importantes rios do Estado. Apesar disso, as matas ciliares foram praticamente dizimadas e substituídas por cultivos de olerícolas, justamente, porque as únicas áreas planas situam-se às margens do rio Canoas, que apresenta ao longo do percurso diferentes graus de perturbação.

Através da Rede Guarani-Serra Geral, desenvolve-se trabalho, através do qual se pretende restaurar as matas ciliares e resgatar a importância, mas priorizando a proteção dos recursos hídricos dentro das possibilidades econômicas da pequena propriedade e a identificação de produtos florestais não madeireiros. Leva-se em consideração também, novos referenciais de restauração, principalmente aqueles relacionados à resiliência ecológica dessas áreas (Reis et al., 2007), como a possibilidade da chegada de propágulos da vizinhança, a presença de regenerantes naturais na área degradada e o resgate da diversidade regional, para garantir a sustentabilidade da comunidade restaurada (Rodrigues et al., 2007).

Nesse sentido, é importante a identificação do potencial uso dos recursos vegetais como perspectiva econômica aos produtores, o que poderia resultar na redução gradual de áreas de APPs cultivadas com culturas agrícolas de alta demanda de agrotóxicos e que exercem alta pressão sobre a qualidade da água superficial. Valorar as florestas e identificar espécies arbóreas medicinais ou condimentares é fundamental, tanto para a subsistência dessas propriedades e a manutenção dos pequenos agricultores nesses locais, quanto para a proteção dos recursos naturais.

Sendo assim, o objetivo desse trabalho foi identificar as espécies arbóreas com potencial de uso medicinal presentes nos remanescentes das matas ciliares de pequenas propriedades do município de Urubici envolvidas em projetos de restauração, bem como determinar potencialidades de emprego para a restauração de áreas degradadas.

\section{MATERIAL E MÉTODO}

\section{Caracterização do local}

As áreas de estudo localizam-se em três pequenas propriedades não contíguas (Figura 1) do município de Urubici (latitude 2800'48"S e longitude 49³5'22"W), situadas em duas comunidades: São José e Campestre. A população desse município é de 10.439 habitantes (IBGE, 2007). O clima é mesotérmico úmido, segundo a classificação de Köppen. O relevo de Urubici é composto por três unidades denominadas Planalto de Lages, Planícies Fluviais e Serra Geral.

As unidades experimentais compreendem áreas de regeneração natural de matas ciliares situadas em planícies aluviais, representadas por áreas planas adjacentes ao rio Canoas, periodicamente inundadas e localizadas paralelamente a lavouras de olericultura.

\section{Estabelecimento das amostragens}

As espécies selecionadas neste estudo foram extraídas do levantamento fitossociológico realizado em outubro de 2008, para o qual se empregou o método dos quadrantes. Foram alocados dois transectos de $100 \mathrm{~m}$ por propriedade, paralelamente ao curso do Rio Canoas na região central da faixa de mata ciliar. A distância entre os pontos sobre o transecto foi de 10 $\mathrm{m}$, totalizando 240 indivíduos arbóreos (80 indivíduos/ propriedade) com $C A P \geq 15 \mathrm{~cm}$. Tendo em vista que os estudos foram realizados em pequenas propriedades, com pequenas faixas de mata ciliar, onde a largura varia de 1-15 metros, optou-se por alocar o transecto paralelamente ao curso do rio.

Todas as espécies amostradas foram coletadas. O material foi herborizado, identificado e doado ao Herbário Lages da Universidade do Estado de Santa Catarina (LUSC). As espécies foram agrupadas nas famílias botânicas segundo definições

Rev. Bras. PI. Med., Botucatu, v.12, n.3, p.322-332, 2010. 

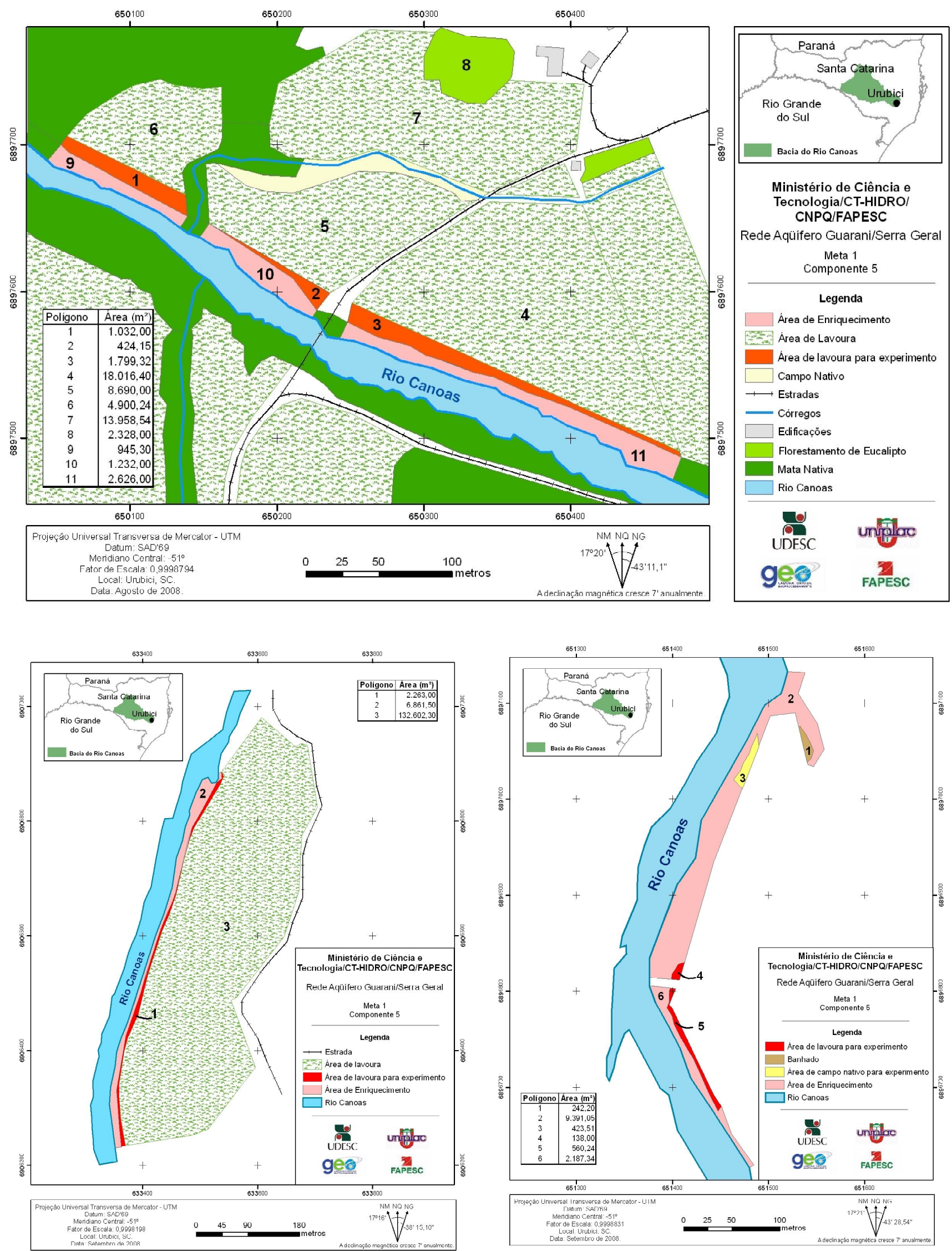

FIGURA 1. Mapas de uso e ocupação do solo das pequenas propriedades rurais de Urubici-SC. Em rosa destaque para remanescentes de mata ciliar onde foram alocados os transectos paralelamente ao curso do rio. 
do Angiosperm Phylogeny Group (APGII, 2003). Para identificação das espécies recorreu-se a chaves dicotômicas e acervo bibliográfico disponível (Lorenzi, 2002a, 2002b; Wanderley et al., 2003; Sobral et al., 2006; Souza \& Lorenzi, 2008; Reitz, 1965).

\section{Potencial medicinal}

Para cada espécie medicinal registrou-se a família, o nome popular, a parte usada e os principais tipos de uso na medicina popular. Foram compilados trabalhos etnobotânicos, etnoecológicos, taxonômicos e florísticos que indicassem ou citassem plantas medicinais da Floresta Atlântica (Reitz, 1965; Lorenzi \& Matos, 2008; Moerman \& Estabrook, 2003; Cruz \& Kaplan, 2004).

\section{Características ecológicas e síndrome de dispersão}

As principais características ecológicas foram listadas de acordo com a descrição da literatura apresentada por Reitz (1965), Lorenzi (2002a; 2002b) e Carvalho (2006).

Para a caracterização da síndrome de dispersão dos diásporos das espécies coletadas, utilizaram-se os critérios e categorias propostas por Van der Pijl (1982), reunidos em três grupos básicos: 1) anemocóricas - espécies que apresentam mecanismos que facilitam a dispersão pelo vento; 2 ) zoocóricas - aquelas que possuem características relacionadas à dispersão por animais; e 3) autocóricas - as espécies que dispersam os diásporos por gravidade ou apresentam mecanismos de autodispersão como a deiscência explosiva, bem como informações registradas na literatura (Giongo \& Waechter, 2007; Rondon-Neto et al., 2001; Piovello et al., 2006; Andreis et al., 2005).

A partir dos trabalhos de Machtans et al. (1996), Pizo (2002), Galetti et al. (2003), Silva (2003), Gressler et al. (2006) e Bechara et al. (2007) foram discutidas as implicações ecológicas dos tipos de síndrome de dispersão para a restauração de áreas degradas.

\section{Classificação das espécies de acordo com grupos ecológicos e recomendação para restauração de áreas degradadas}

As espécies foram classificadas de acordo com os grupos ecológicos (Gandolfi et al., 1995): $i$. pioneiras, ii. secundárias iniciais e iii. secundárias tardias, conforme registros na literatura (Araújo et al., 2005; Moscovich, 2006; Ramos \& Boldo, 2007; Scherer et al., 2007).

Através de consultas bibliográficas, as espécies foram categorizadas em recomendadas (R) e não recomendadas (NR) para restauração de áreas degradas, conforme informações dos autores Knapik \& Maranhão (2007), Nappo et al. (2004), Ferreira \& Dias (2004), Lorenzi (2002a; b) e Silva et al. (2003).

\section{RESULTADO E DISCUSSÃO}

\section{Espécies dos remanescentes florestais com Potencial Medicinal}

Dos 240 indivíduos arbóreos amostrados, 197 indivíduos pertencentes à 22 espécies de 15 famílias botânicas (Tabela 1), são citados na literatura especializada por apresentarem potencialidades medicinais, representando $82,08 \%$ do total de indivíduos amostrados, o que caracteriza a importância ecológica de espécies arbóreas medicinais nas matas ciliares das pequenas propriedades de Urubici.

Entre as famílias mais abundantes destacam-se Euphorbiaceae, Rosaceae, Myrtaceae, Lauraceae e Anacardiaceae, respectivamente com 52 , 42, 31, 22 e 14 indivíduos (Tabela 1), sendo que Sebastiania commersoniana apresenta-se dominante em todas as propriedades estudadas, seguida de Prunus myrtifolia e da mirtácea Blepharocalyx salicifolius. Segundo Reitz (1965), S. commersoniana é uma espécie muito frequente nas planícies aluviais, comumente dominante, formando $60-80 \%$ de estrato contínuo das florestas de galeria. Dias et al. (1998) confirmam a importância dessa espécie na caracterização das matas ciliares da região sul do Brasil, especialmente nas florestas de araucária e Kolb et al.(1998) indicam a espécie para restauração de ambientes ciliares degradados.

A elevada abundância de algumas espécies como S. commersoniana, P. myrtifolia e B. salicifolius está associada à adaptabilidade das mesmas às áreas de solo úmido ou mesmo inundáveis. A adaptação a esses ambientes fragmentados e 0 isolamento da vegetação induz segundo Hanson et al. (1990), as situações de dominância de poucas espécies, diminuindo a diversidade, a equidade e a riqueza biológica. Porém, a abundância pode não significar que sejam bastante utilizadas para fins medicinais.

Segundo Moerman \& Estabrook (2003), em estudo sobre o uso de plantas medicinais pelos nativos americanos, há preferência por espécies medicinais de algumas famílias em relação a outras, independente do tamanho dessas famílias. Essa preferência pode estar ligada a características culturais e a forma como a informação é transmitida, uma vez que de acordo com Marodin et al. (2001), em pesquisa realizada no Rio Grande do Sul, os usos terapêuticos das plantas não possui muita influência de livros ou cursos, mas é atribuído ao aprendizado com as gerações anteriores, ou seja, o conhecimento passa de mãe para filho.

A vegetação primária do território catarinense está dividida em seis formações vegetais distintas, entre as quais, destaca-se, no Planalto Serrano, a Floresta de Araucária, composta de sub-mata rica em representantes especialmente das famílias 
TABELA 1. Espécies arbóreas medicinais observadas em remanescentes degradados de mata ciliar de pequenas propriedades rurais onde estão sendo realizados projetos de restauração.

\begin{tabular}{|c|c|c|c|c|c|c|}
\hline FAMÍLIA/Espécie & $\begin{array}{l}\text { Nome } \\
\text { coletor }\end{array}$ & $\begin{array}{l}\text { Nome coletor } / \mathrm{N}^{\circ} \\
\text { do colet or }\end{array}$ & $\begin{array}{l}\text { Parte } \\
\text { usada }\end{array}$ & Uso & Fonte & FR \\
\hline $\begin{array}{l}\text { ANACARDIACEAE } \\
\text { Lithraea brasiliensis Marchand }\end{array}$ & Bugreiro & $\begin{array}{l}\text { Chaves, C.L.; } \\
\text { Manfredi-Coimbra, } \\
\text { S./11 }\end{array}$ & Folha & $\begin{array}{l}\text { Adstringente, cicatrizante, } \\
\text { antiinflamatório, diarréias, } \\
\text { antiúlcera, anti-reumática, }\end{array}$ & $\begin{array}{l}\text { Pedroso et al. } \\
\text { (2007) }\end{array}$ & 6 \\
\hline $\begin{array}{l}\text { Schinus therebinthifolius } \\
\text { Raddi }\end{array}$ & $\begin{array}{l}\text { Aroeira- } \\
\text { vermelha }\end{array}$ & $\begin{array}{l}\text { Chaves, C.L.; } \\
\text { Manfredi-Coimbra, } \\
\text { S./77 }\end{array}$ & $\begin{array}{l}\text { Casca } \\
\text { Folha } \\
\text { Ramos } \\
\text { novos }\end{array}$ & $\begin{array}{l}\text { Depurativa, cicatrizante, } \\
\text { antinflamatório, ntitérmica, } \\
\text { Alti-reumática, antiúlcera, } \\
\text { cicatrizantes } \\
\begin{array}{l}\text { Alti-reumática, antiúlcera, } \\
\text { cicatrizantes. Limpeza e } \\
\text { branquemento dos dentes. }\end{array}\end{array}$ & $\begin{array}{l}\text { Reitz (1965). } \\
\text { Lorenzi \& Matos } \\
\quad(2008) \\
\text { Reitz (1965) }\end{array}$ & 8 \\
\hline $\begin{array}{l}\text { ARAUCARIACEAE } \\
\text { Araucaria angustifolia (Bertol.) } \\
\text { Kuntze }\end{array}$ & Araucária & $\begin{array}{l}\text { Chaves, C.L.; } \\
\text { Manfredi-Coimbra, } \\
\text { S./41 }\end{array}$ & Folha & $\begin{array}{l}\text { Bronquite, asma, tosses, } \\
\text { catarro, debilidade } \\
\text { orgânica, diurética. }\end{array}$ & $\begin{array}{l}\text { Pedroso et al. } \\
\text { (2007) }\end{array}$ & 5 \\
\hline $\begin{array}{l}\text { CELASTRACEAE } \\
\text { Maytenus muelleri Mart. ex } \\
\text { Reiss }\end{array}$ & $\begin{array}{l}\text { Espinheira- } \\
\text { santa }\end{array}$ & $\begin{array}{l}\text { Chaves, C.L.; } \\
\text { Manfredi-Coimbra, } \\
\text { S./42 }\end{array}$ & Folha & $\begin{array}{l}\text { Câncer de pele (decocto). } \\
\text { Tratamento de úlceras, } \\
\text { indigestão, dispepsia e } \\
\text { gastrites crônicas. }\end{array}$ & $\begin{array}{l}\text { Lorenzj \& Matos } \\
\qquad(2008)\end{array}$ & 2 \\
\hline $\begin{array}{l}\text { DICKSONIACEAE } \\
\text { Dicksonia sellowiana Hook. }\end{array}$ & Xaxim-bugio & $\begin{array}{c}\text { Chaves, C.L.; } \\
\text { Manfredi-Coimbra, } \\
\text { S./418 }\end{array}$ & $\begin{array}{r}\text { Parte da } \\
\text { inserção } \\
\text { da folha } \\
\end{array}$ & $\begin{array}{l}\text { Hemostático (coagulação } \\
\text { do sangue). }\end{array}$ & Reitz (1965) & 1 \\
\hline $\begin{array}{l}\text { EUPHORBIACEAE } \\
\text { Sebastiana commersoniana } \\
\text { (Baill.) L.B.Sm.\&B.J.Downs }\end{array}$ & Branquilho & $\begin{array}{l}\text { Chaves, C.L.; } \\
\text { Manfredi-Coimbra, } \\
\text { S. } / 03\end{array}$ & Casca & $\begin{array}{l}\text { Blenorrágica (gonorréia), } \\
\text { leu corrágica (corrimento). }\end{array}$ & Marques (2007) & 52 \\
\hline $\begin{array}{l}\text { FLACORTIACEAE } \\
\text { Casearia decandra N. J. } \\
\text { Jacquin }\end{array}$ & Guaçatunga & $\begin{array}{l}\text { Chaves, C.L.; } \\
\text { Manfredi-Coimbra, } \\
\text { S./438 } \\
\end{array}$ & $\mathrm{NI}$ & Úlceras sórdidas & Moreira (1862) & 2 \\
\hline $\begin{array}{l}\text { LAURACEAE } \\
\text { Nectandra megapotamica }\end{array}$ & $\begin{array}{l}\text { Canela- } \\
\text { preta }\end{array}$ & $\begin{array}{l}\text { Chaves, C.L.; } \\
\text { Manfredi-Coimbra, } \\
\text { S. } / 93\end{array}$ & $\begin{array}{l}\text { Folha e } \\
\text { casca }\end{array}$ & $\begin{array}{l}\text { Calmante, tosses, gripes, } \\
\text { furúnculos. }\end{array}$ & $\begin{array}{l}\text { Alves et al. } \\
\quad(2008)\end{array}$ & 2 \\
\hline $\begin{array}{l}\text { Ocoteae puberula (Rich.) } \\
\text { Nees }\end{array}$ & $\begin{array}{l}\text { Canela- } \\
\text { guaicá }\end{array}$ & $\begin{array}{l}\text { Chaves, C.L.; } \\
\text { Coimbra, S.M./159 }\end{array}$ & $\begin{array}{l}\text { Flores e } \\
\text { casca }\end{array}$ & $\begin{array}{l}\text { Problemas estomacais, } \\
\text { tratamento externo de }\end{array}$ & $\begin{array}{l}\text { Pedroso et al. } \\
\text { (2007) }\end{array}$ & 0 \\
\hline Ocotea pulchella (Nees) Mez & $\begin{array}{l}\text { Canela- } \\
\text { lajeana }\end{array}$ & $\begin{array}{l}\text { Chaves, C.L.; } \\
\text { Manfredi-Coimbra, } \\
\text { S./406 }\end{array}$ & $\begin{array}{c}\text { Casca e } \\
\text { folha }\end{array}$ & $\begin{array}{l}\text { tumores. } \\
\text { Estomática, emenagogas, } \\
\text { tônicas do útero. }\end{array}$ & & 14 \\
\hline $\begin{array}{l}\text { MIMOSOIDEAE } \\
\text { Mimosa scabrella Benth. }\end{array}$ & Bracaatinga & $\begin{array}{c}\text { Chaves, C.L.; } \\
\text { Manfredi-Coimbra, } \\
\text { S.M./145 } \\
\end{array}$ & $\begin{array}{c}\text { Casca e } \\
\text { caule }\end{array}$ & Combate às coceiras. & $\begin{array}{c}\text { Marquesini } \\
(1995)\end{array}$ & 9 \\
\hline $\begin{array}{l}\text { MYRSINACEAE } \\
\text { Myrsine coriacea (Sw.) R. Br. }\end{array}$ & Capororoca & $\begin{array}{l}\text { Chaves, C.L.; } \\
\text { Manfredi-Coimbra, } \\
\text { S./202 }\end{array}$ & $\begin{array}{l}\text { Casca e } \\
\text { folhas }\end{array}$ & $\begin{array}{l}\text { Diurético, afecções das } \\
\text { vias urinárias, depurativo } \\
\text { do sangue. }\end{array}$ & Marques (2007) & 5 \\
\hline $\begin{array}{l}\text { MYRTACEAE } \\
\text { Acca sellowiana (Berg.) Burret }\end{array}$ & $\begin{array}{l}\text { Goiaba- } \\
\text { serrana }\end{array}$ & $\begin{array}{l}\text { Chaves, C.L.; } \\
\text { Manfredi-Coimbra, } \\
\text { S./123 }\end{array}$ & Folha & $\begin{array}{l}\text { Diarréia, baixar pressão, } \\
\text { antioxidante, antifúngica, } \\
\text { antimicrobiana, } \\
\text { anticancerígena }\end{array}$ & $\begin{array}{l}\text { Ritter et al. } \\
(2002) \\
\text { Karami et al. } \\
(2008)\end{array}$ & 2 \\
\hline $\begin{array}{l}\text { Blepharocalyx salicifolius } \\
\text { (Kunth.)Berg }\end{array}$ & Murta & $\begin{array}{l}\text { Chaves, C.L.; } \\
\text { Manfredi-Coimbra, } \\
\text { S./132 }\end{array}$ & Folha & $\begin{array}{l}\text { Diarréia, leucorréia, uretrite, } \\
\text { prolapso retal, males da } \\
\text { bexiga. }\end{array}$ & $\begin{array}{l}\text { Bontempo et al. } \\
\text { (2007). Mors et } \\
\text { al. }(2000)\end{array}$ & 21 \\
\hline
\end{tabular}


TABELA 1. Espécies arbóreas medicinais observadas em remanescentes degradados de mata ciliar de pequenas propriedades rurais onde estão sendo realizados projetos de restauração.

...continuação

\begin{tabular}{|c|c|c|c|c|c|c|}
\hline FAMÍLIA/Espécie & $\begin{array}{l}\text { Nome } \\
\text { coletor }\end{array}$ & $\begin{array}{l}\text { Nome coletor } / \mathrm{N}^{\circ} \\
\text { do colet }\end{array}$ & $\begin{array}{l}\text { Parte } \\
\text { usada }\end{array}$ & Uso & Fonte & FR \\
\hline $\begin{array}{l}\text { Campomanesia xanthocarpa } \\
\text { Berg. }\end{array}$ & Guabiroba & $\begin{array}{l}\text { Chaves, C.L.; } \\
\text { Manfredi-Coimbra, } \\
\text { S./133 }\end{array}$ & Folhas & $\begin{array}{l}\text { Colesterd, circulação, gripe, } \\
\text { diurético, diarréia, males da } \\
\text { bexiga. }\end{array}$ & $\begin{array}{l}\text { Dorigoni et al. } \\
(2001) ; \text { Piva } \\
(2002)\end{array}$ & 4 \\
\hline Eugenia uniffora L. & Pitanga & $\begin{array}{c}\text { Chaves, C.L.: } \\
\text { Manfredi-Coimbra, } \\
\text { S./224 }\end{array}$ & Folhas & $\begin{array}{l}\text { Calmante, diurético, gota, } \\
\text { reumatismo, antìérmico, } \\
\text { diarréia, hi pertensão, }\end{array}$ & $\begin{array}{l}\text { Alves et al. } \\
(2008) \\
\text { Sanchonete } \\
(1985)\end{array}$ & 1 \\
\hline $\begin{array}{l}\text { Myrrinhium atropurpure um } \\
\text { Schott }\end{array}$ & Murtilho & $\begin{array}{c}\text { Chaves, C.L.; } \\
\text { Manfredi-Coimbra, } \\
\text { S./103 }\end{array}$ & Folhas & Atividade artimicrobiana. & $\begin{array}{l}\text { Rotman et al. } \\
(2003)\end{array}$ & 3 \\
\hline $\begin{array}{l}\text { PODOCARPACEAE } \\
\text { Podocarpus lambertii (Klotzsh } \\
\text { ex Eichler) }\end{array}$ & $\begin{array}{l}\text { Pinheiro- } \\
\text { bravo }\end{array}$ & $\begin{array}{c}\text { Chaves, C.L.; } \\
\text { Manfredi-Coimbra, } \\
\text { S./124 }\end{array}$ & Folha & $\begin{array}{l}\text { Anemias, doenças das } \\
\text { glândulas e astenia, } \\
\text { fortificante, estimulante. }\end{array}$ & Körbes (1995) & 6 \\
\hline $\begin{array}{l}\text { QUILLAJACEAE } \\
\text { Quillaja brasiliensis (St. Hill.) } \\
\text { Mart. }\end{array}$ & $\begin{array}{l}\text { Pão-de- } \\
\text { sabão }\end{array}$ & $\begin{array}{c}\text { Chaves, C.L.; } \\
\text { Manfredi-Coimbra, } \\
\text { S. } / 200\end{array}$ & Casca & Adstringente, muailaginosa & $\begin{array}{l}\text { Mentz et al. } \\
\quad(1997)\end{array}$ & 2 \\
\hline $\begin{array}{l}\text { RHAMNACEAE } \\
\text { Scutia buxifolia Reissek }\end{array}$ & Coronilha & $\begin{array}{c}\text { Chaves, C.L.; } \\
\text { Manfredi-Coimbra, } \\
\text { S./206 }\end{array}$ & $\begin{array}{l}\text { Casca e } \\
\text { raiz }\end{array}$ & $\begin{array}{l}\text { Febrífuga, antiinflamatória, } \\
\text { disenterias. }\end{array}$ & $\begin{array}{l}\text { Morel et al. } \\
(2005)\end{array}$ & 2 \\
\hline $\begin{array}{l}\text { ROSACEAE } \\
\text { Prunus myrtifolia (Linnaeus) } \\
\text { Urban }\end{array}$ & $\begin{array}{c}\text { Pessegueiro } \\
\text {-bravo }\end{array}$ & $\begin{array}{c}\text { Chaves, C.L.; } \\
\text { Manfredi-Coimbra, } \\
\text { S./214 }\end{array}$ & Folha & Asmas, tosses (infusão) & $\begin{array}{l}\text { Mentz et al. } \\
\quad(1997)\end{array}$ & 42 \\
\hline $\begin{array}{l}\text { SAPINDACEAE } \\
\text { Matayba elaeagnoides } \\
\text { Radl kofer }\end{array}$ & Camboatá & $\begin{array}{c}\text { Chaves, C.L.; } \\
\text { Manfredi-Coimbra, } \\
\text { S./91 }\end{array}$ & Folha & $\begin{array}{l}\text { Moderador do apetite, } \\
\text { estimulante } \\
\text { doenças } \\
\text { coxual, } \\
\text { como tosses e bronquirites }\end{array}$ & $\begin{array}{l}\text { Pedroso et al. } \\
(2007)\end{array}$ & 2 \\
\hline
\end{tabular}

Myrtaceae e Lauraceae (Reitz, 1965), daí a importância dessas famílias nesse estudo.

Cruz \& Kaplan (2004) salientam que espécies de Myrtaceae são empregadas frequentemente, para conter distúrbios gastrointestinais, estados hemorrágicos e doenças infecciosas, sendo as partes mais usadas as folhas, cascas e também os frutos, que são comumente consumidos.

$\mathrm{Na}$ medicina popular, as Lauraceae apresentam utilização variada, com ações antireumática, depurativa, gástrica, anti-sifilítica e outras. Destacam-se principalmente os gêneros Ocotea, que apresenta o maior número de espécies com potencial medicinal e Aniba (Marques, 2001).

\section{Síndromes de Dispersão de Sementes}

A principal síndrome de dispersão é a zoocórica, observada em mais de $77 \%$ das espécies medicinais que se encontram na área. De todas as espécies com potencial medicinal amostradas, apenas cinco não apresentam dispersão zoocórica (Tabela 2).

Nas floretas tropicais a forma mais freqüente de dispersão de sementes é a zoocórica, sendo que segundo Morellato \& Leitão-Filho (1992) cerca de 60 a $90 \%$ delas são adaptadas a esse tipo de transporte. Para Floresta Ombrófila Mista, Rondon Neto et al. (2001) afirmam que $75,7 \%$ das espécies arbóreas são zoocóricas, 18,9\% anemocóricas e 5,4\% autocóricas. Liebsch \& Acra (2007) registram, para o mesmo ecossistema $65,1 \%$ das espécies com diásporos zoocóricos, 23,6\% anemocóricos, 2,2\% autocóricos e 9,0\% de plantas com síndrome não determinada.

A fauna é essencial para a dispersão de sementes de remanescentes próximos, podendo contribuir efetivamente para a regeneração das florestas (Parrota et al., 1997; Martins, 2007). Daí a importância do etno-conhecimento, principalmente de caçadores, indicando quais plantas em frutificação exercem grande atração sobre os animais, que, ao visitarem essas plantas para se alimentarem, atraem seus predadores (Reis et al., 2007). Nesse sentido, as espécies da família Myrtaceae merecem atenção, pois segundo Pizo (2002), todas as espécies de mirtáceas ocorrentes no Brasil produzem frutos carnosos, com variada morfologia, principalmente quanto ao tamanho, coloração e número de sementes, e com diferentes grupos de dispersores, entre os quais 


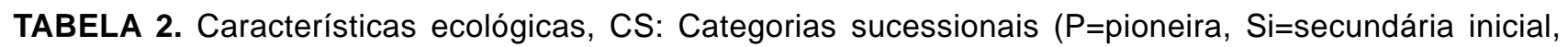
St=secundária tardia, SD: Síndrome de dispersão ( $A n=$ anemocoria, Au=autocoria, e $Z=z o o c o r i a) ~ e ~ R R$ : Recomendação de uso para restauração ambiental ( $R=$ recomendada, $N R=$ não recomendada, ID=Informação desconhecida) das espécies amostradas nas matas ciliares de pequenas propriedades rurais situadas às margens do Rio Canoas. Urubici, Outubro/2008.

\begin{tabular}{|c|c|c|c|c|}
\hline Espécie & Características ecológicas & SD & ES & $\mathbf{R R}$ \\
\hline Lithraeae brasiliensis & $\begin{array}{l}\text { Heliófita ou de luz difusa, indiferente quanto ao tipo de solo } \\
\text { (Reitz, 1965) }\end{array}$ & Z & $P$ & $\mathrm{R}$ \\
\hline Schinus therebinthifolius & $\begin{array}{l}\text { Espécie heliófita ou de luz difusa, indiferente quanto ao tipo } \\
\text { de solo (Reitz, 1965). Comum em várzeas (Lorenzi, 2002a) }\end{array}$ & Z & $P$ & $\mathrm{R}$ \\
\hline Araucaria angustifólia & $\begin{array}{l}\text { Perenifólia, heliófita, característica de regiões de altitude } \\
\text { (Lorenzi, 2002a). }\end{array}$ & $\mathrm{Au}$ & $P$ & ID \\
\hline Maytenus muelleri & $\begin{array}{l}\text { Perenifólia, heliófita ou de luz difusa, seletiva higrófita, ocorre } \\
\text { predominantemente em várzes (Lorenzi, 2002b). }\end{array}$ & Z & $\mathrm{Si}$ & $\mathrm{R}$ \\
\hline Dicksonia sellowiana & $\begin{array}{l}\text { Cresce em lugares sombreados de solo pantanoso em } \\
\text { banhados ou baixadas úmidas (Reitz, 1965) }\end{array}$ & - & - & NR \\
\hline Sebastiana commersoniana & $\begin{array}{l}\text { Decídua, heliófita, seletiva higrófita, adaptada à solos úmidos } \\
\text { (Lorenzi, 2002a). }\end{array}$ & $\mathrm{Au}$ & St & $\mathrm{R}$ \\
\hline Casearia decandra & $\begin{array}{l}\text { Esciófita, seletiva higrofita, prefere solos úmidos ou } \\
\text { compactados (Reitz, 1965) }\end{array}$ & Z & $\mathrm{Si}$ & $\mathrm{R}$ \\
\hline Nectandra megapotamica & Heliófita, indiferente as condiçoes do solo (Reitz, 1965) & Z & $\mathrm{Si}$ & $\mathrm{R}$ \\
\hline Ocotea puberula & $\begin{array}{l}\text { Semidecídua, heliófita, indiferente às condições edáficas } \\
\text { (Lorenzi, 2002a). }\end{array}$ & Z & $\mathrm{Si}$ & $\mathrm{R}$ \\
\hline Ocotea pulchella & Semidecídua e heliófita (Lorenzi, 2002a). & Z & $\mathrm{Si}$ & $\mathrm{R}$ \\
\hline Mimosa scabrella & $\begin{array}{l}\text { Semidecídua e heliófita, indiferente quanto às características } \\
\text { edáficas (Lorenzi, 2002a). }\end{array}$ & An & $\mathrm{P}$ & $\mathrm{R}$ \\
\hline Myrsine coriácea & Perenifolia, heliófita, seletiva higrofita (Lorenzi, 2002a) & Z & $\mathrm{P}$ & $\mathrm{R}$ \\
\hline Acca sellowiana & $\begin{array}{l}\text { Semidecídua, heliófita, seletiva higrófita, comum em solos } \\
\text { úmidos (Lorenzi, 2002a). }\end{array}$ & Z & $\mathrm{P}$ & $\mathrm{R}$ \\
\hline Blepharocalyx salicifolius & $\begin{array}{l}\text { Exigente em luz (Carvalho, 2006), perenifólia, seletiva } \\
\text { higrófila, heliófita até esciófita (Lorenzi, 2002b). }\end{array}$ & Z & $\mathrm{Si}$ & $\mathrm{R}$ \\
\hline $\begin{array}{l}\text { Campomanesia } \\
\text { xanthocarpa }\end{array}$ & $\begin{array}{l}\text { Decídua, mesófila até heliófita e seletiva higrófita. Abundante } \\
\text { nas partes úmidas das matas de pinhais (Lorenzi, 2002a) }\end{array}$ & Z & $\mathrm{Si}$ & $\mathrm{R}$ \\
\hline Eugenia uniflora & $\begin{array}{l}\text { Heliofita, prefere orla de capoes e margens de curso d`água } \\
\text { (Marchiori \& Sobral, 1997) }\end{array}$ & Z & St & $\mathrm{R}$ \\
\hline Myrrinhium atropurpureum & Mesófita até ciófita e seletiva higrófita (Reitz, 1965). & Z & $\mathrm{Si}$ & $\mathrm{R}$ \\
\hline Podocarpus lambertii & Perenifólia e heliófita (Lorenzi, 2002a). & Z & $\mathrm{P}$ & $\mathrm{R}$ \\
\hline Quillaja brasiliensis & $\begin{array}{l}\text { Heliófita ou esciófita, indiferente as condições físicas do solo } \\
\text { (Reitz, 1965) }\end{array}$ & An & $\mathrm{P}$ & $\mathrm{R}$ \\
\hline Scutia buxifolia & Higrófita e ciófita, rara e estranha (Reitz, 1965). & Z & $P$ & ID \\
\hline Prunus myrtifolia & $\begin{array}{l}\text { Heliófita ou esciófita, indiferente as condições físicas do solo } \\
\text { (Reitz, 1965). }\end{array}$ & Z & $P$ & $\mathrm{R}$ \\
\hline Matayba elaeagnoides & $\begin{array}{l}\text { Semidecídua, mesófita, seletiva higrófita, comum em solos } \\
\text { úmidos (Lorenzi, 2002a). }\end{array}$ & Z & St & $\mathrm{R}$ \\
\hline
\end{tabular}

Rev. Bras. PI. Med., Botucatu, v.12, n.3, p.322-332, 2010. 
grandes aves frugívoras, macacos e morcegos (Gressler et al., 2006), podendo essas espécies serem consideradas bagueiras.

O papel das plantas bagueiras é justamente o de atrair fauna diversificada, e por isso, devem ser utilizadas como promotoras de encontros interespecíficos dentro de áreas degradadas, exercendo o papel de nucleadoras (Reis et al., 1999), especialmente, em ambientes fragmentados, onde em consequência da ausência ou baixa abundância de animais frugívoros, o sucesso reprodutivo das plantas, medido pela remoção de seus frutos pode ser drasticamente afetado (Galetti et al., 2003). Assim, a manutenção dos corredores florestais ripários facilita a movimentação de indivíduos juvenis de aves conforme demonstrado por Machtans et al. (1996), servindo ainda de abrigo aos mesmos.

Por outro lado, a estreita faixa de mata ciliar nas unidades experimentais e no município como um todo, cria condições características de borda, e segundo Galetti et al. (2003), há evidências de que a abundância de pequenas aves frugívoras é maior na borda dos fragmentos; em conseqüência, plantas situadas nas bordas tem os frutos removidos com maior frequência do que plantas no interior dos fragmentos e pelo fato de freqüentarem também as adjacências, as plantas de borda podem contribuir sobremaneira para a chuva de sementes.

Esse efeito traz consequências diretas sobre a seleção das espécies que devem ser utilizadas para enriquecimento das áreas adjacentes em restauração. Considerando-se que os vertebrados frugívoros são importantes no fluxo de sementes de áreas conservadas para degradadas, a atração dos mesmos para áreas em restauração pode ser feita pelo plantio de espécies zoocóricas pioneiras e secundárias iniciais com o intuito de promover a reconstrução de interações da comunidade (Rodrigues \& Gandolfi, 2000), o que pode ser feito especialmente, pelo plantio de espécies que produzem frutos carnosos ou arilados, que são consumidos por aves e mamíferos frugívoros, prevendo-se a manutenção da disponibilidade constante de frutos ao longo do ano (Silva, 2003) e também, pela utilização de poleiros artificiais (Bechara et al., 2007).

A síndrome de dispersão é um dos processos mais importantes da regeneração natural de florestas tropicais, assim como da colonização de habitats (Van der Pijl, 1982), e por isso, precisa ser considerada. A resolução SMA-8 de $7 / 3 / 2007$, do estado de São Paulo, prevê no seu Artigo 11, que para recuperação de áreas com algum tipo de cobertura florestal nativa remanescente, uma das recomendações a ser observada é que nos casos de plantio de espécies arbóreas para fins de restauração as áreas devem ser enriquecidas com espécies não pioneiras, priorizando-se espécies nativas da flora regional presentes em alguma das categorias de ameaça (vulnerável, em perigo, criticamente em perigo ou presumivelmente extinta), bem como espécies zoocóricas.

\section{Classificação das espécies em grupos ecológicos e recomendação para restauração de áreas degradadas}

$\mathrm{Na}$ distribuição das espécies em grupos ecológicos, as pioneiras (10) ocupam a primeira posição com $45,45 \%$, seguidas das secundárias iniciais (8) com $36,36 \%$ e 3 secundárias tardias, $13,63 \%$, sendo que Dicksonia sellowiana não foi incluída em nenhum critério (Tabela 2). A inserção das espécies nos grupos sucessionais esbarrou nas divergências de critérios empregados por diferentes autores. Silva et al. (2003) citam também essa dificuldade, além da própria resposta diferencial de uma mesma espécie frente às diferentes condições ambientais em função das características genéticas do indivíduo.

Quanto à frequência, o maior número (Tabela 1) de indivíduos arbóreos medicinais amostrados está incluído na categoria de pioneiras (89), seguidos das secundárias tardias (54) e secundárias iniciais (53).

O conhecimento dos grupos ecológicos é necessário ao entendimento do estágio sucessional em que se encontram os remanescentes de mata ciliar desse estudo e para seleção de espécies para enriquecimento das áreas. Durante a sucessão secundária, os grupos de espécies adaptados as condições de maior luminosidade, colonizam as áreas abertas e crescem rapidamente, fornecendo 0 sombreamento para o estabelecimento de espécies mais tardias da sucessão (Martins, 2007). Assim, os critérios grupo ecológico e síndrome de dispersão, são considerados para a restauração. Nesse sentido, os dados sugerem uma fase de transição da floresta ciliar do estágio médio para o avançado de regeneração de acordo com a Resolução 04/1994 do CONAMA.

Contudo, um fator limitante que não pode deixar de ser considerado é o manejo das propriedades. Embora haja condições ecológicas favoráveis ao estabelecimento de secundárias tardias, especialmente sombreamento, caracterizando um modelo de facilitação (Connel \& Slatyer, 1977), a regeneração é bastante baixa nesses locais, em função de serem utilizados para pastejo, uma vez que a principal atividade das propriedades é a bovinocultura de leite.

O potencial medicinal das espécies registradas, especialmente das famílias Myrtaceae e Lauraceae, que desempenham também papel funcional relevante para a restauração das áreas ciliares degradadas devido à atratividade que exercem sobre à fauna para promoção de interações

Rev. Bras. PI. Med., Botucatu, v.12, n.3, p.322-332, 2010. 
extremamente importantes para as florestas ficou evidenciado. Das 22 espécies medicinais, para apenas três não são encontrados registros na literatura de recomendação para uso em restauração de áreas degradadas, Araucaria angustifolia, Dicksonia sellowiana e Scutia buxifolia, todas amostradas com baixa freqüência (Tabela 2), o que indica uma compatibilidade de uso para a medicina popular e para a restauração de áreas degradadas, as duas questões centrais dessa pesquisa.

$\mathrm{Na}$ busca do desenvolvimento econômico das pequenas propriedades rurais de Urubici, tem-se que considerar aspectos tanto ambientais quanto da identidade do local, como por exemplo, o ecoturismo, muito difundido no município, apontando atividades que satisfaçam as condições legais de exploração dos recursos naturais de forma sustentável, aspecto fundamental para a permanência do homem no campo.

Nessas pequenas propriedades rurais, onde os recursos para implantação de projetos de restauração de áreas degradadas são limitados, é possível promover interações ecológicas capazes de recuperar funções importantes para o equilíbrio ambiental utilizando-se espécies arbóreas da flora local adaptadas às características edafo-climáticas locais, e também passíveis de exploração comercial, como as espécies arbóreas medicinais, que atendem a um conjunto de características importantes do ponto de vista funcional e econômico.

Assim, a extração ordenada e planejada de espécies medicinais arbóreas pode ser uma maneira de valorar as APPs dessas pequenas propriedades, respeitando-se o previsto na Legislação (Lei no 11.428 de 22 de dezembro de 2006, que dispõe sobre a utilização e proteção da vegetação nativa do Bioma Mata Atlântica), para a busca da sustentabilidade econômica da pequena propriedade. O uso de folhas apresenta caráter de conservação do recurso vegetal, pois a retirada das mesmas, se não for excessiva, não compromete o desenvolvimento e a reprodução da planta. Essa seria ainda uma medida apoiada pelo governo, que nas últimas décadas tem estimulado significativamente o estudo do potencial dos produtos florestais não-madeireiros (PFNMs) em desempenharem importante papel complementar à madeira e à agricultura nos meios de subsistência rurais e em contribuir para a conservação e o manejo sustentável das florestas (Mariot \& Reis, 2006). Contudo, trabalhos preliminares sobre o levantamento de espécies e potencial de uso, começam agora a ser desenvolvidos, na perspectiva da elaboração de uma proposta para manejo num futuro próximo.

\section{AGRADECIMENTO}

Aos órgãos de fomento MCT/CNPq/CTHIDRO e FAPESC/FUNJAB, que apoiaram a pesquisa através do Projeto Rede Guarani/Serra Geral. A equipe técnica de geoprocessamento da Rede Guarani/Serra Geral, pela produção dos mapas.

\section{REFERÊNCIA}

ALVES, E.O. et al. Levantamento etnobotânico e caracterização de plantas medicinais em fragmentos florestais de Dourados-MS. Ciência Agrotécnica, v.32, n.2, p.651-8, 2008.

ANDREIS, C. et al. Estudo fenológico em três fases sucessionais de uma floresta estacional decidual no município de Santa Tereza, RS, Brasil. Árvore, v.29, n.1, p.55-63, 2005.

Angiosperm Phylogeny Group. An update of the Angiosperm Phylogeny Group classification for the orders and families of flowering plants: APG II. Botany Journal Linnean Society, v.141, n.4, p.399-436, 2003. ARAÚJO, F.S. et al. Florística da vegetação arbustivoarbórea colonizadora de uma área degradada por mineração de caulim, em Brás Pires, MG. Árvore, v.29, n.6, p.983-92, 2005.

BONTEMPO, P. et al. Feijoa sellowiana derived natural Flavone exerts anti-cancer action displaying HDAC inhibitory activities. International Journal of Biochemistry \& Cell Biology, v.39, n.10, p.1902-14, 2007.

BRASIL. Ministério da Agricultura, Pecuária e Abastecimento. Boas Práticas Agrícolas (BPA) de plantas medicinais, aromáticas e condimentares. Brasília: MAPA/SDC, 2006. 48p. (Plantas Medicinais \& Orientações Gerais para o Cultivo, 1).

BECHARA, F.C. et al. Unidades demonstrativas de restauração ecológica através de técnicas nucleadoras de biodiversidade. Revista Brasileira de Biociências, v.5, supl. 1, p.9-11, 2007.

CARVALHO, P.E.R. Espécies arbóreas brasileiras. v.2. Colombo: Embrapa Florestas, 2006. 627p.

CONNEL, J.H.; SLATYER, R.O. Mechanisms of succession in natural communities and their role in community stability and organization. The Americam Naturalist, v.111, n.982, p.1119-44, 1977.

CRUZ, A.V.M.; KAPLAN, M.A.C. Uso medicinal de espécies das famílias Myrtaceae e Melastomataceae no Brasil. Floresta e Ambiente, v.11, n.1, p.47-52, 2004. DIAS, M.C. et al. Composição florística e fitossociologia do componente arbóreo das florestas ciliares do rio lapó, na Bacia do rio Tibagi, Tibagi, PR. Revista Brasileira de Botânica, v.21, n.2, p.183-95, 1998.

DORIGONI, P.A. et al. Levantamento de dados sobre plantas medicinais de uso popular no Município de São João Polésine, RS, Brasil. I-relação entre enfermidades e espécies utilizadas. Revista Brasileira de Plantas Medicinais, v.4, n.1, p.69-79, 2001.

FERREIRA, D.A.C.; DIAS, H.C.T. Situação atual da mata ciliar do ribeirão São Bartolomeu em Viçosa, MG. Árvore, v.28, n.4, p.617-23, 2004.

GALLETI, M.; COSTA, C.; GAZETTA, E. Effects of Forest fragmentation, anthropogenic edges and fruit color on the consumption of ornithochoric fruits. Biological Conservation, v.111, n.2, p.269-93, 2003.

GANDOLFI, S.; LEITÃO-FILHO, H.F.; BEZERRA, C.L.F.

Rev. Bras. PI. Med., Botucatu, v.12, n.3, p.322-332, 2010. 
Levantamento florístico e caráter sucessional das espécies arbustivo-arbóreas de uma floresta semidecídua no município de Guarulhos, SP. Revista Brasileira de Biologia, v.55, p.753-67, 1995.

GIONGO, C.; WAECHTER, J.L. Composição florística e espectro de dispersão das espécies arbóreas de uma floresta mista com Podocarpus, Rio Grande do Sul. Revista Brasileira de Biociências, v.5, n.2, p.333-5, 2007.

GRESSLER, E.; PIZO, M.A.; MORELLATO, L.P.C. Polinização e dispersão de sementes em Myrtaceae do Brasil. Revista Brasileira de Botânica, v.29, n.4, p.50930, 2006.

HANSON, J.S.; MALASON, G.P.; ARMSTRONG, M.P. Landscape fragmentation and dispersal in a modelo $f$ riparian Forest dynamics. Ecological Modelling, v.49, p.277-96, 1990.

IBGE. Resultados da amostra do censo demográfico 2007. Rio de Janeiro: IBGE, 2007. Disponível em: <http:// www.ibge.gov.br/cidadesat>. Acesso em: 02 mar. 2009. KARAMI, M.; SALEHI, H.; NAGHSHVAR, F. Study of histopathology and antioxidant activity of methanolic extract of Feijoa Sellowiana against dosage induced by MDMA in mouse liver. Pharmacologyonline, v.3, p.31521, 2008.

KNAPIK, P.; MARANHÃO, L.T. Avaliação da revegetação em Área de Mineração, Região de Inundação do Rio Iguaçu, Araucária, PR. Revista Brasileira de Biociências, v.5, supl.1, p.507-9, 2007.

KOLB, R. et al. Anatomia ecológica de Sebastiania commersoniana (Baillon) Smith \& Dows (Euphorbiaceae) submetida ao alagamento. Revista Brasileira de Botânica, v.21, n.3, p.305-12, 1998. KÖRBES, V.C. Manual de plantas medicinais. Francisco Beltrão: Associação de Estudos, Orientação e Assistência Rural, 1995. 188p.

LIEBSCH, D.; ACRA, L.A. Síndromes de dispersão de diásporos de um fragmento de floresta ombrófila mista em Tijucas do Sul, PR. Revista Acadêmica, v.5, n.2, p.167-75, 2007.

LORENZI, H. Árvores brasileiras: manual de identificação e cultivo de plantas arbóreas do Brasil. 4.ed. São Paulo: Instituto Plantarum, 2002a. v.1, 368p.

LORENZI, $H$. Árvores brasileiras: manual de identificação e cultivo de plantas arbóreas do Brasil, v.2, 2.ed. São Paulo: Instituto Plantarum, 2002b, 368p.

LORENZI, H.; MATOS, F.J.A. Plantas medicinais no Brasil: nativas e exóticas. 2.ed. São Paulo: Instituto Plantarum, 2008. 544p.

MACHTANS, C.S.; VILLARD, M.A.; HANSON, S.J. Use of riparian buffer strips as movement corridors by forest birds. Conservation Biology, v.10, p.1366-79, 1996.

MARIOT, A.; REIS, M.S. Biodiversidade e sua importância como fonte de plantas medicinais. Revista de Ciências Agroveterinárias, v.5, n.1, p.53-61, 2006.

MARODIN, S.M.; BAPTISTA, L.R.M. O uso de plantas com fins medicinais no município de Dom Pedro de Alcântara, Rio Grande do Sul, Brasil. Revista Brasileira de Plantas Medicinais, v.4, n.1, p.57-68, 2001.

MARQUES, C.A. Importância econômica da família Lauraceae Lindl. Floresta e Ambiente, v.8, n.1, p.195206, 2001.

MARQUES, T.P. Subsídios à recuperação de formações florestais ripárias da Floresta Ombrófila Mista do
Estado do Paraná, a partir do uso espécies fontes de produtos florestais não-madeiráveis. 2007. 244p. Dissertação (Mestrado, Produção Vegetal) Departamento de Fitotecnia e Fitossanitarismo, Universidade Federal do Paraná, Curitiba.

MARQUESINI, N.R. Plantas usadas como medicinais pelos índios do Paraná e Santa Catarina, sul do Brasil: Guarani, Kaingang, Xogleng, Ava-Guarani, Kraô e Cayuá. 1995. 290p. Dissertação (Mestrado - Área de Concentração Produção Vegetal) - Departamento de Fitotecnia e Fitossanitarismo, Universidade Federal do Paraná, Curitiba.

MARCHIORI, J.N.C.; SOBRAL, M. Dendrologia das Angiospermas: Myrtales. Santa Maria: Ed. UFSM, 1997. 304p.

MARTINS, S.V. Recuperação de Matas Ciliares. Viçosa: CPT. 2007. 255p.

MENTZ, L.A.; LUTZEMBERGER, L.C.; SCHENKEL, E.P. Da flora medicinal do Rio Grande do Sul: notas sobre a obra de D’Ávila (1910). Caderno de Farmácia, v.13, n.1, p.25-48, 1997.

MOERMAN, D.E.; ESTABROOK, G.F. Native Americans' choice of species for medicinal use is dependent on plant family: confirmation with meta-significance analysis. Journal of Ethnopharmacology, v.87, p.51-9, 2003.

MOREIRA, N.J. Diccionario de plantas medicinaes brasileiras. Rio de Janeiro: Typographia do Correio Mercantil, 1862. 144p.

MOREL, A.F. et al. Cyclopeptide alkaloids from Scutia buxifolia Reiss and their antimicrobial activity. Phytochemistry, v.66, p.2571-6, 2005.

MORELLATO, L.P.; LEITÃO-FIHO, H.F. Padrões de frutificação e dispersão na Serra do Japi. In: MORELLATO, L.P. (Coord.). História natural da Serra do Japi: ecologia e preservação de uma floresta no Sudeste do Brasil. São Paulo: UNICAMP/FAPESP, 1992. p.112-41.

MORS, W.B.; RIZZINI, C.T.; PEREIRA, N.A. Medicinal plants of Brazil. Michigan: Reference Publications, 2000. $501 \mathrm{p}$.

MOSCOVICH, F.A. Dinâmica de crescimento de uma floresta ombrófila mista em Nova Prata, RS. 2006. 135p. Tese (Área de Concentração em Manejo Florestal) Programa de Pós-Graduação em Engenharia Florestal, Universidade Federal de Santa Maria, Santa Maria.

NAPPO, M.N. et al. Dinâmica da estrutura fitossociológica da regeneração natural em sub-bosque de Mimosa scabrella Bentham em área minerada, em Poços de Caldas, MG. Árvore, v.28, n.6, p.811-29, 2004.

OLIVEIRA, F.Q. et al. Potencial das plantas medicinais como fonte de novos antimaláricos: espécies indicadas na bibliografia etnomédica brasileira. Revista Brasileira de Plantas Medicinais, v.5, n.2, p.23-31, 2003.

PARROTA, J.A.; KNOWLES, O.H.; WUNDERLEJR, J.M. Development of floristic diversity in 10-year-old restoration Forest on a bauxite mined site in Amazonia. Forest Ecolology and Management, v.99, p.21-42, 1997.

PEDROSO, K. et al. Levantamento de plantas medicinais arbóreas e ocorrência em floresta ombrófila mista. Ambiência, v.3, n.1, p.40-50, 2007.

PIOVELLO, V.R.; PETENON, D.; JESUS, F.M. Chuva de sementes em fragmentos de Floresta Atlântica (São Paulo, SP, Brasil), sob diferentes situações de 
conectividade, estrutura florestal e proximidade da borda. Acta Botanica Brasilica, v.20, n.4, p.845-59, 2006. PIVA, M.G. O caminho das plantas medicinais: estudo etnobotânico. Rio de Janeiro: Mondrian, 2002. 313p. PIZO, M.A. The seed dispersers and fruit syndromes of Myrtaceae in Brazilian Atlantic forest. In: LEVEY, D.J.; SILVA, W.R.; GALETTI, W.R. Frugivores and seed dispersers: biodiversity and conservation perspectives. Wallingford: Cab Publishing. 2002. p.129-43.

RAMOS, A.J.K.; BOLDO, E. Diversidade florística e aspectos fitossociológicos de formações florestais em estágio sucessional secundário na floresta ombrófila mista, município de Caxias do Cul-RS. Revista Brasileira de Agroecologia, v.2, n.1, p.111-6, 2007. REIS, A.; TRES, D.R.; SCRIOT, E.C. Restauração na floresta ombrófila mista através da sucessão natural. Pesquisa Florestal Brasileira, n.55, p.67-73, 2007. REIS, A.; ZAMBONIN, R.; NAKAZONO, E.M. Recuperação de áreas florestais degradadas utilizando a sucessão e as interações planta-animal. Conselho Nacional da Reserva da Biosfera da Mata Atlântica/São Paulo: Governo do Estado de São Paulo, 1999. 42p. (Séries Cadernos da Biosfera, 14).

REITZ, R. Flora Ilustrada Catarinense. Itajaí: Herbário Barbosa Rodrigues, 1965. 149p.

RITTER, M.R. et al. Plantas usadas como medicinais no município de Ipê, RS, Brasil. Revista Brasileira de Farmacognosia, v.12, n.2, p.51-62, 2002.

RODRIGUES, R.R.; GANDOLFI, S. Conceitos, tendências e ações para a recuperação de florestas ciliares. In: RODRIGUES, R.R.; LEITÃO-FILHO, H.F. (Eds.). Matas ciliares: conservação e recuperação. São Paulo: EDUSP/FAPESP, 2000. p.235-47.

RODRIGUES, R.R. et al. Atividades de adequação ambiental e restauração florestal do LERF/ESALQ/USP. Pesquisa Florestal Brasileira, n.55, p.7-21, 2007. RONDON-NETO, R.M.; WATZLAWICK, L.F.; CALDEIRA, M.V.W. Diversidade florística e síndromes de dispersão de diásporos das espécies arbóreas de um fragmento de floresta ombrófila mista. Revista Ciências Exatas e Naturais, v.3, n.2, p.209-16. 2001.

ROTMAN, A. et al. Aromatic plants from Yungas. Part III. Composition and antimicrobial activity of Myrrhinium atropurpureum Schott var. octandrum Bentham essential oil. Flavour and Fragrance Journal, v.18, n.3, p.211-4, 2003. SANCHONETE, M.C. Frutíferas nativas úteis a fauna de arborização urbana. Porto Alegre: FEPLAN, 1985. $311 \mathrm{p}$.

SCHERER, A.; MARASCHIN-SILVA, F.; BAPTISTA, L.R.M. Regeneração arbórea num capão de restinga no Rio Grande do Sul, Brasil. Inheringia. Série Botânica, v.62, n.1-2, p.89-98, 2007.

SILVA, W.R. A importância das interações planta-animal nos processos de restauração. In: KAGEYAMA, P.Y. et al. Restauração ecológica de ecossistemas naturais. Botucatu: FEPAF, 2003. p.77-90.

SILVA, A.F. et al. Composição florística e grupos ecológicos das espécies de um trecho de floresta semidecídua submontana da fazenda São Geraldo, Viçosa-MG. Revista Árvore, v.27, n.3, p.311-9, 2003. SOBRAL, M.; JARENKOW, J.A.; BRACK, P. Flora arbórea e arborescente do Rio Grande do Sul, Brasil. São Carlos: Rima, 2006. 350p.

SOUZA, V.C.; LORENZI, H. Botânica sistemática: guia ilustrado para identificação de famílias de fanerógamas nativas e exóticas do Brasil, baseado no APGIl. 2.ed. São Paulo: Instituto Plantarum de Estudos da Flora, 2008. $703 p$.

SUYENAGA, E.S. et al. O risco do uso de plantas medicinais indicadas por ervateiros no tratamento da sinusite em Porto Alegre. Estudos, v.34, n.11/12, p. 83342, 2007.

VAN DER PIJL, L. Principles of dispersal in higher plants. 3.ed. Berlim: Springer-Verlag, 1982. 162p.

WANDERLEY, M.G. L. et al. Flora fanerogâmica do estado de Santo Paulo. São Paulo: Rima, 2003. 367p. 